\section{PSQ-145 SEVERITY OF MEDICATION RECONCILIATION ERRORS IN ELDERLY PATIENTS PRODUCED IN THE EMERGENCY DEPARTMENT}

'B Montero Llorente*, 'I Taladriz Sender, 'N Espadas Hervás, 'M Muñoz García, ${ }^{2}$ B Montero Errasquín, ${ }^{1} \mathrm{AM}$ Álvarez Díaz, ${ }^{1} \mathrm{E}$ Delgado Silveira, ${ }^{1} \mathrm{~T}$ Bermejo Vicedo. ${ }^{1}$ Hospital Ramon Y Cajal, Pharmacy Department, Madrid, Spain; ${ }^{2}$ Hospital Ramon Y Cajal, Geriatric Department, Madrid, Spain

\subsection{6/ejhpharm-2019-eahpconf.578}

Background Medication errors are one of the main causes of morbidity in hospitalised patients. To minimise them at admission, it is convenient to perform a correct medication reconciliation that avoids discrepancies in the chronic treatment.

Purpose To assess the severity of the medication reconciliation errors (MRE) produced in the Emergency Department (ED) in patients admitted to the Acute Geriatric Unit (AGU).

To describe the incidence of the MRE detected.

Material and methods An observational, prospective study was conducted in a general hospital.

All patients admitted to the AGU between 1 October 2017 and 30 April 2018 were included, excluding those in palliative care.

The chronic treatment, collected by the pharmacist in an interview with the patient or main caregiver, was compared with the prescribed treatment in the ED.

We recorded the following variables: age, sex, number of chronic pathologies and chronic medications, type of discrepancy (justified or MRE), type of MRE according to a consensus document, whether the error reached the patient or not and its severity (using the NCCMERP classification with the collaboration of a specialist in geriatrics).

Results We included 351 patients, 238 females (67.8\%), with a mean age of $92.7 \pm 3.9$ years. The median of chronic pathologies was 5 (0-13) and of chronic medications 7 (1-24): 282 $(80.3 \%)$ were polymedicated.

A total of 1473 discrepancies were identified in 328 (93.4\%) patients: 300 discrepancies (20.4\%) were considered as MRE in 151 (43\%) patients, with an average of $2 \pm 0.7$ errors per patient.

Regarding the severity of the MRE detected, 104 (34.7\%) were classified as category C, $117(39 \%)$ as category D and $27(9 \%)$ as category E: 52 MRE (17.3\%) were intercepted on time.

The most common MRE were omission errors, 149 (49.7\%), wrong dose errors, 70 (23.3\%) and commission errors, 37 (12.3\%).

Conclusion Most of the MRE were not detected on time and reached the patient: one in 10 caused temporary damage (category E).

In almost half of the patients admitted to the AGU, at least one MRE was detected, being the most frequent omission errors.

These results reflect the need to implement medication reconciliation programmes in the ED.

\section{REFERENCES AND/OR ACKNOWLEDGEMENTS}

No conflict of interest.

\section{PSQ-146 DRUGS INTERACTION ANALYSIS OF PRESCRIPTIONS OF A TEACHING HOSPITAL: FREQUENCY AND GRAVITY}

${ }^{1} \mathrm{M}$ Mseddi ${ }^{*},{ }^{1} \mathrm{M}$ Khrouf, ${ }^{1} \mathrm{~A}$ Hamdi, ${ }^{2} \mathrm{M}$ Turki. ${ }^{1}$ Faculty of Pharmacy- University of Monastir, Pharmacology Department, Monastir, Tunisia; ${ }^{2}$ Teaching Hospital Hedi Chaker, Pharmacy Department, Sfax, Tunisia

\subsection{6/ejhpharm-2019-eahpconf.579}

Background Medical iatrogenesis represents a large proportion of avoidable direct and indirect health costs.

Purpose Evaluate quantitatively and qualitatively potential drug interactions by pharmaceutical assessment of hospitalised patients and outpatients' prescriptions.

Material and methods A prospective observational monocentric one-day study including 590 prescriptions for (in/out) patients in a teaching hospital.

The analysis of prescription has been conducted with the help of the Vidal 2016 database and Theriaque.org (updated October 2017), the correlation of polypharmacy with drugs interactions by SPSS software v23.

Results Among the 590 prescriptions analysed corresponding to 1901 lines of prescription, an average of $3.23 \pm 1.918$ (1, 11) of drugs per prescription and a median of 3 .

Four-hundred and fifty-three prescriptions (76.8\%) contained at least two drugs. We identified 128 prescriptions with at least one interaction (prevalence of 27.7\%). A total of 165 interactions were counted with an average of 0.43 and a median of 0 interactions per prescription with at least two medications (0.8). A significant correlation has been demonstreted between number of drugs prescribed and number of interactions $(r$ pearson $=0.61$ with $p<0.05$ ). There were three contraindications, 22 drug combinations discouraged (13.3\%), 90 requiring precautions for use $(54.5 \%)$ and 50 associations to consider (30.3\%).

Different drug classes were incriminated in the occurrence of interactions: top of the list were cardiovascular drugs $(45.5 \%)$ followed by drugs of the central nervous system $(12.9 \%)$. The most specifically implicated drugs were captopril (10.8\%), furosemide (6.3\%) and acenocoumarol $(4.8 \%)$

Among the adverse effects that could be generated by these interactions, we note, first, cardiovascular effects at $37.4 \%$, followed by metabolic disorders and nutrition with $18.4 \%$. The most commonly observed adverse reactions were renal failure (26 cases) and orthostatic hypotension (23 cases).

This work allows us to establish a list of frequent drugs involved in the most frequent and serious drug interactions.

Conclusion Prevention of iatrogenicity is a complex problem. The pharmaceutical validation step is primordial in drug dispensing and requires a rich database of drug interactions that should be consulted in a systematic way. Following our study, an action plan was set up with the editing of a validation manual and a training schedule for pharmacists.

\section{REFERENCES AND/OR ACKNOWLEDGEMENTS}

No conflict of interest. 